\title{
Theoretical and Experimental Understanding of Hydrogen Evolution Reaction Kinetics in Alkaline Electrolytes with Pt-Based Core-Shell Nanocrystals
}

Jeonghyeon Kim, ${ }^{\dagger, \#}$ Haesol Kim, $,{ }^{\ddagger}, \#$ Won-Jae Lee, ${ }^{\dagger}$ Bibi Ruqia, ${ }^{\dagger}$ Hionsuck Baik, ${ }^{\S}$ Hyung-Suk Oh, Seung-Min Paek, ${ }^{\dagger}$ Hyung-Kyu Lim,,${ }^{*}{ }^{\perp}$ Chang Hyuck Choi, ${ }^{*,+}$ and Sang-Il Choi*,†

†Department of Chemistry and Green-Nano Materials Research Center, Kyungpook National University, Daegu 41566, Korea

\$School of Materials Science and Engineering, Gwangju Institute of Science and Technology, Gwangju 61005 Republic of Korea

${ }^{\S}$ Korea Basic Science Institute (KBSI), Seoul 02841, Korea

"Clean Energy Research Center, Korea Institute of Science and Technology (KIST), Seoul 02792, Korea

${ }^{\perp}$ Division of Chemical Engineering and Bioengineering, Kangwon National University, Chuncheon, Gangwon-do 24341, Korea

\#These authors contributed equally to this work.

*Corresponding authors: hklim@kangwon.ac.kr (H.-K.L.), chchoi@gist.ac.kr (C.H.C.), sichoi@knu.ac.kr (S.-I.C.) 


\section{Materials and Methods}

Reagent. Sodium tetrachloropalladate(II) $\left(\mathrm{Na}_{2} \mathrm{PdCl}_{4}, 98 \%\right)$, citric acid (CA, 99\%), poly(vinyl pyrrolidone) (PVP, Mw $\approx 55,000$ ), N, N-dimethylformamide (DMF, 99\%), benzyl alcohol (BA 99\%) oleylamine (OAm, 70\%), oleic acid (OAc, 90\%) were purchased from Sigma Aldrich. Platinum(II) acetylacetonate ( $\left.\mathrm{Pt}(\mathrm{acac})_{2}, \mathrm{Pt} 48.0 \%\right)$ was purchased from Alfa Aesar. Ethanol, acetone, acetic acid glacial, n-hexane, and diethyl ether were purchased from Duksan. Vulcan XC-72R carbon black was obtained from Cabot Corporation. Deionized (DI) water with a resistivity of $18.2 \mathrm{M} \Omega \cdot \mathrm{cm}$ was used.

Material characterization. Transmission electron microscopy (TEM) images were taken using a HT-7700 microscope (HITACHI, Japan) operated at $100 \mathrm{kV}$ by drop casting the nanoparticle dispersions on carbon-coated copper grids and drying under ambient conditions. High-resolution TEM studies were carried out in a Titan G2 ChemiSTEM Cs Probe microscope. Aberration-corrected imaging and high spatial resolution energy dispersive X-ray spectroscopy (EDS) were performed at FEI Double Cs-corrected Titan3 G2 60-300 S/TEM instrument with Chemi-STEM technology and FEI Nanoport in Eindhoven using a Titan Probe Cs TEM 300kV with Chemi-STEM technology. EDS elemental mapping data were collected using a higher efficiency detection system (Super-X detector with XFEG); it integrates 4 FEI-designed Silicon Drift Detectors (SDDs) very close to the sample area. Compared to conventional EDX detector with Schottky FEG systems, ChemiSTEM produces up to 5 times the X-ray generation with the X-FEG, and up to 10 times the X-ray collection with the Super-X detector. X-ray diffraction (XRD) patterns were collected with X-ray diffracter (PANalytical X'pert PRO-MPD/MRD) using a $\mathrm{Cu}-\mathrm{K} \alpha$ radiation at $40 \mathrm{kV}$ and $25 \mathrm{~mA}$. Ultraviolet photoelectron spectroscopy (UPS) analyses were performed using an AXIS Ultra DLD model (KRATOS Inc.) with a He-I UV source. X-ray absorption spectroscopy (XAS) was carried out at 8C beamline of Pohang Accelerator Laboratory (PAL) in Korea, in which XAS data acquisition and analysis were performed by the standard procedure. ${ }^{1,2}$ Metal contents in nanocrystals were determined by inductively coupled plasma-atomic emission spectrometry (ICP-AES, Perkin-Elmer, Optima 7300DV).

Synthesis of Pd octahedra. $180 \mathrm{mg}$ of $\mathrm{CA}$ and $105 \mathrm{mg}$ of PVP $(\mathrm{Mw} \approx 55,000)$ were dissolved in a mixture containing $3 \mathrm{~mL}$ of ethanol and $5 \mathrm{~mL}$ of water placed in a $25 \mathrm{~mL}$ glass vial, which was pre-heated at $80^{\circ} \mathrm{C}$ for $10 \mathrm{~min}$ in an oil bath under magnetic stirring. Then, $3 \mathrm{~mL}$ of water 
containing $57 \mathrm{mg}$ of $\mathrm{Na}_{2} \mathrm{PdCl}_{4}$ was added into the pre-heated mixture. The vial was capped, and maintained at $80{ }^{\circ} \mathrm{C}$ for $3 \mathrm{~h}$. The final product was collected by centrifugation at 12,000 rpm for $10 \mathrm{~min}$. Pd octahedra were then re-dispersed in $14 \mathrm{~mL}$ of BA for the use as the seeds of Pd@Pt core-shell octahedra. ${ }^{3}$

Conversion of Pd octahedra into $\boldsymbol{\beta}$-Pd hydride octahedra. After centrifugation of $7 \mathrm{~mL}$ BA containing $10 \mathrm{mg}$ Pd octahedra seeds, Pd octahedra were dispersed in a mixture of $15 \mathrm{~mL}$ of DMF and $30 \mathrm{mg}$ of PVP. The reaction mixture was heated at $160{ }^{\circ} \mathrm{C}$ for $16 \mathrm{~h}$ in an oil bath under magnetic stirring. The final product was collected by centrifugation, and re-dispersed in $7 \mathrm{~mL}$ of BA for the use as the seeds of PdH@Pt core-shell octahedra. ${ }^{3}$

Synthesis of Pd@Pt $\mathbf{P t}_{\mathbf{n L}}$ core-shell octahedra. x mg of $\mathrm{Pt}(\mathrm{acac})_{2}(\mathrm{x}=3,6$, and $10 \mathrm{mg}$ for $\mathrm{Pd} @ \mathrm{Pt}_{1 \mathrm{~L}}, \mathrm{Pd} @ \mathrm{Pt}_{2-3 \mathrm{~L}}$ and Pd@Pt $\mathrm{P}-5 \mathrm{~L}$, respectively), $2 \mathrm{~mL}$ of OAm (70\%) and $1 \mathrm{~mL}$ of OAc were added into $7.0 \mathrm{~mL}$ of BA including the Pd octahedral seeds and then heated to $130{ }^{\circ} \mathrm{C}$ under an argon atmosphere with magnetic stirring. After reaction temperature reached $130{ }^{\circ} \mathrm{C}, \mathrm{Ar}$ purging was stopped and the mixture was further heated up to $200{ }^{\circ} \mathrm{C}$ at a heating rate of $7{ }^{\circ} \mathrm{C}$ $\min ^{-1}$ under $\mathrm{CO}$ atmosphere. The flow rate of $\mathrm{CO}$ gas was set at $5 \mathrm{~cm}^{3} \mathrm{~min}^{-1}$. When temperature of the flask reached $200{ }^{\circ} \mathrm{C}$, CO purging was stopped and heating was continued for $40 \mathrm{~min}$. After cooled down to room temperature and being added $5 \mathrm{~mL}$ ethanol and $15 \mathrm{~mL} \mathrm{n}$-hexane, was centrifuged at 3,000 rpm for 10 min. $^{4,5}$

Synthesis of PdH@Pt $\mathbf{n t}_{\mathbf{n L}}$ octahedra. x mg Pt(acac) $)_{2}\left(\mathrm{x}=3,6\right.$, and $10 \mathrm{mg}$ for $\mathrm{PdH} @ \mathrm{Pt}_{\mathrm{ML}}$, PdH@Pt 2 -3L and PdH@Pt 4 -5L, respectively), 2 mL OAm (70\%) and 1 mL OAc were added into $7.0 \mathrm{~mL}$ of BA including the $10 \mathrm{mg}$ of $\mathrm{PdH}$ octahedral seeds and heated to $130{ }^{\circ} \mathrm{C}$ under an $\mathrm{Ar}$ atmosphere with magnetic stirring. After reaction temperature reached $130{ }^{\circ} \mathrm{C}$, Ar purging was stopped and the mixture was heated up to $200{ }^{\circ} \mathrm{C}$ at a heating rate of $7{ }^{\circ} \mathrm{C} \mathrm{min}{ }^{-1}$ under $\mathrm{CO}$ atmosphere. The flow rate of $\mathrm{CO}$ gas was set at $5 \mathrm{~cm}^{3} / \mathrm{min}$. When temperature of the flask reached $200{ }^{\circ} \mathrm{C}$, CO purging was stopped and heating was continued for $40 \mathrm{~min}$. After cooling down to room temperature, the reaction mixture was added to $5 \mathrm{~mL}$ of ethanol and $15 \mathrm{~mL}$ of n-hexane and then centrifuged at 3,000 rpm for $10 \mathrm{~min}$.

Preparation of Pd@Pt $\mathbf{P L} / \mathbf{C}$ and $\mathbf{P d H} @ \mathbf{P t}_{\mathbf{n L}} / \mathbf{C}$ catalysts. A suspension of 15 mg Pd@Pt $\mathrm{t}_{\mathrm{nL}}$ or $\mathrm{PdH} @ \mathrm{Pt}_{\mathrm{nL}}$ octahedra and $60 \mathrm{mg}$ of Vulcan XC-72R carbon black was dispersed in a mixture 
containing $15 \mathrm{~mL}$ of ethanol and $5 \mathrm{~mL}$ of acetic acid to wash organic contaminants from the surface of the nanocrystals. ${ }^{4,5}$ The mixture was then sonicated for $2 \mathrm{~h}$ and the resulting $\mathrm{Pd} @ \mathrm{Pt}_{\mathrm{nL}} / \mathrm{C}$ or $\mathrm{PdH} @ \mathrm{Pt}_{\mathrm{nL}} / \mathrm{C}$ was collected by centrifugation. Each catalysts were washed three times with ethanol and dried by Ar.

Synthesis of Pt octahedra/C catalyst. $20 \mathrm{mg}$ of $\mathrm{Pt}(\mathrm{acac})_{2}$ and $105 \mathrm{mg}$ of PVP were added into $10 \mathrm{~mL}$ of BA and heated at $200{ }^{\circ} \mathrm{C}$ for $1 \mathrm{~h}$ in an oil bath with magnetic stirring. Resulting $\mathrm{Pt}$ octahedra were collected by centrifugation at $3000 \mathrm{rpm}$ for $10 \mathrm{~min}$, and re-dispersed in $15 \mathrm{~mL}$ of ethanol (Figure S7). Then $40 \mathrm{mg}$ of Vulcan XC-72R carbon black was added into the ethanol containing Pt octahedra and sonicated for $2 \mathrm{~h}$. The resulting $\mathrm{Pt}$ octahedra/C catalyst was collected by centrifugation at 3,000 rpm for $10 \mathrm{~min}$. Catalyst was washed three times with ethanol and dried in Ar atmosphere. ${ }^{6}$

Electrochemical measurements. Electrochemical measurements were performed with a modulated speed rotator (RRDE-3A, ALS) and a potentiostat (VMP3, Bio-Logic Science Instruments) in a three-electrode cell. Graphite rod and $\mathrm{Ag} / \mathrm{AgCl}$ (RE-16 for strong alkaline media, EC-Frontier) electrodes were used as counter and reference electrodes, respectively. The electrochemical cell was made of Teflon and the reference electrode was doubly separated with a PEEK bridge tube to avoid glassware dissolution and halogen poisoning. ${ }^{7,8}$ A 3-mmdiameter glassy carbon rotating disk electrode (A-011169, ALS) was used as the working electrode after mirror polishing with alumina slurry $(0.05 \mu \mathrm{m}, \mathrm{R} \& \mathrm{~B}$ Inc.). The catalyst ink was prepared by dispersing the catalysts of $5 \mathrm{mg}$ in an aqueous solution containing isopropyl alcohol and $5 \mathrm{wt} \%$ Nafion ${ }^{\circledR}$ solution. Thin film electrodes were made by pipetting the catalyst ink onto the glassy carbon $\left(0.071 \mathrm{~cm}^{2}\right)$ with a precious metal loading of $7.5 \mu \mathrm{g} \mathrm{cm}^{-2}$. Commercial Pt/C (HiSPEC-3000, Johnson-Matthey) electrode was also prepared and analyzed to evaluate the validity of our experimental conditions.

Ar- or $\mathrm{H}_{2}$-saturated $0.1 \mathrm{M} \mathrm{KOH}$, which was prepared with ultrapure water $(>18.2 \mathrm{M} \Omega$, Arium mini ${ }^{\circledR}$, Satorius) and KOH (99.99\% trace metals basis, Sigma-Aldrich), was used as an electrolyte. The reference electrode was calibrated against a Pt electrode in the $\mathrm{H}_{2}$-saturated electrolyte. All potentials reported in this work were converted to the RHE scale. Prior to the electrochemical analysis, catalysts were electrochemically cleaned by 50 cycles of cyclic voltammetry $(\mathrm{CV})$ in a potential range of $0.05-1.00 \mathrm{~V}_{\mathrm{RHE}}$ at a $200 \mathrm{mV} \mathrm{s}^{-1}$ scan rate. Upper potential limit (UPL) was limited to $1.00 \mathrm{~V}_{\mathrm{RHE}}$ to avoid the surface re-ordering. ${ }^{9}$ Hydrogen 
evolution reaction (HER)/hydrogen oxidation reaction (HOR) activity was measured in $\mathrm{H}_{2}-$ saturated electrolyte at a rotation speed of $1,600 \mathrm{rpm}$ with a scan rate of $5 \mathrm{mV} \mathrm{s}^{-1}$. The internal resistance $\left(R_{\mathrm{S}}\right)$ was determined by electrochemical impedance spectroscopy at $0.05 \mathrm{~V}_{\mathrm{RHE}}$ for the $I R$ compensation. The HER/HOR activity was evaluated using the exchange current density $\left(j_{0}\right)$, which was obtained by fitting kinetic current density $\left(j_{\mathrm{k}}\right)$ with Bulter-Volmer equation as follows; ${ }^{10}$

$$
j_{\mathrm{k}}=j_{0}\left[\exp \left(\frac{\alpha F \eta}{R T}\right)-\exp \left(\frac{-(1-\alpha) F \eta}{R T}\right)\right]
$$

where $j_{\mathrm{k}}$ is the kinetic current density, $\alpha$ is the asymmetric factor, $F$ is the Faraday constant $\left(96,485 \mathrm{C} \mathrm{mol}^{-1}\right), \eta$ is the overpotential, $R$ is the gas constant, and $T$ is the temperature. The $j_{\mathrm{k}}$ is calculated from the following equations.

$$
\begin{gathered}
\frac{1}{j}=\frac{1}{j_{\mathrm{k}}}+\frac{1}{j_{\mathrm{d}}} \\
\eta_{\text {diffusion }}=-\frac{R T}{n F} \ln \left(1-\frac{j_{\mathrm{d}}}{j_{\text {lim }}}\right)
\end{gathered}
$$

where $j$ is the measured current density, $j_{\mathrm{d}}$ is the diffusion-limiting current density, $\eta_{\text {diffusion }}$ is the Nernstian diffusion overpotential, and $j_{\text {lim }}$ is the limiting current density of HOR. The HER polarization curves were also measured in Ar-saturated electrolyte to obtain Tafel slope without interference from the HOR. The electrochemical surface area $\left(\mathrm{ECSA}_{\mathrm{CO}}\right)$ was analyzed by electrochemical CO stripping. ${ }^{11}$ After $\mathrm{CO}$ adsorption at $0.05 \mathrm{~V}_{\mathrm{RHE}}$ and consecutive removal of $\mathrm{CO}$ dissolved in the electrolyte, two cycles of $\mathrm{CV}$ were conducted in the potential range of $0.05-1.20 \mathrm{~V}_{\mathrm{RHE}}$ with a $50 \mathrm{mV} \mathrm{s}^{-1}$ scan rate. Despite surface re-ordering at the high UPL of $>1$ $\mathrm{V}_{\mathrm{RHE}}$, the UPL of $1.2 \mathrm{~V}_{\mathrm{RHE}}$ was chosen for full $\mathrm{CO}$ oxidation to $\mathrm{CO}_{2}$.

Computational Details. The first-principles density functional theory (DFT) simulations were carried out using the Vienna Ab initio Simulation Package (VASP) software ${ }^{12}$ for determining the $\mathrm{H}$ binding energy and various properties from the electronic structures. All calculations were performed with the revised-Perdew-Burke-Ernzerh (RPBE) exchange-correlation functional, ${ }^{13}$ and the projector-augmented-wave (PAW) method under a plane-wave up to an energy of $450 \mathrm{eV}$. The gamma-centered k-point mesh of $8 \times 8 \times 1$ was used for $(\sqrt{3} \times$ $\sqrt{3}) R 30^{\circ}$ unit periodic slab geometry of $\operatorname{Pt}(111), \operatorname{Pd}(111)$, and $\operatorname{PdH}(111)$. After the full relaxation of metal atoms in slab models, except the bottom layer fixed in their bulk-truncated positions, only the $\mathrm{H}$ atoms are allowed to optimize. The $\mathrm{H}$ binding enthalpy with respect to 
the gaseous $\mathrm{H}_{2}$ state is converted to the $\mathrm{H}$ binding free energy by adding $0.24 \mathrm{eV}$ to account the change of zero-point energy and entropy during binding process. For large-scale cluster models, the Spanish Initiative for Electronic Simulations with Thousands of Atoms (SIESTA) ${ }^{14}$ software was used with the basis-set parameters used in the study elsewhere ${ }^{15}$ and 150 Ry of mesh cut-off energy. Due to the non-periodic condition, we only used gamma point reciprocal space sampling. 

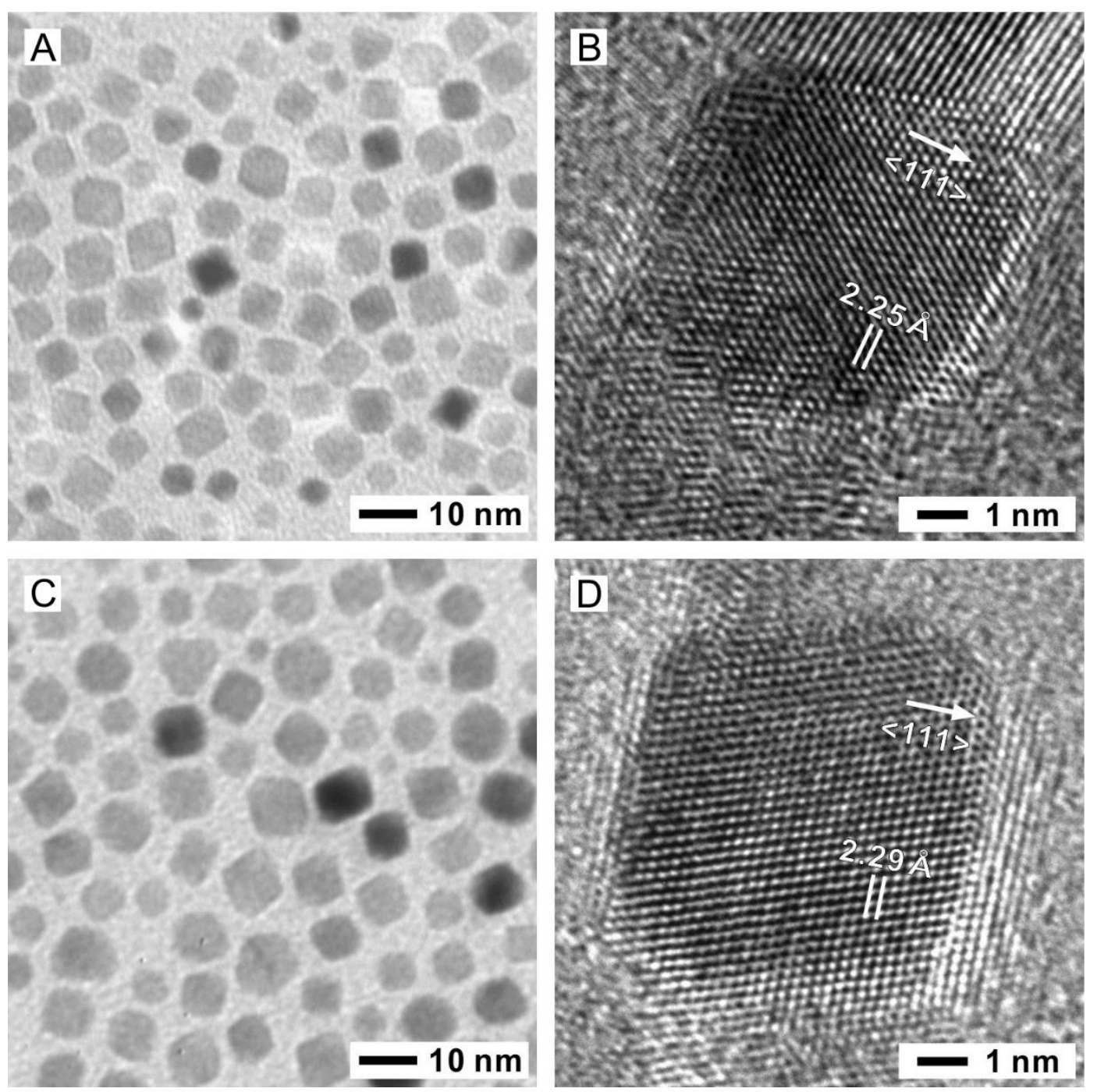

Figure S1. Low- and high-resolution TEM images of (A, B) Pd octahedra and (C, D) PdH octahedra. 

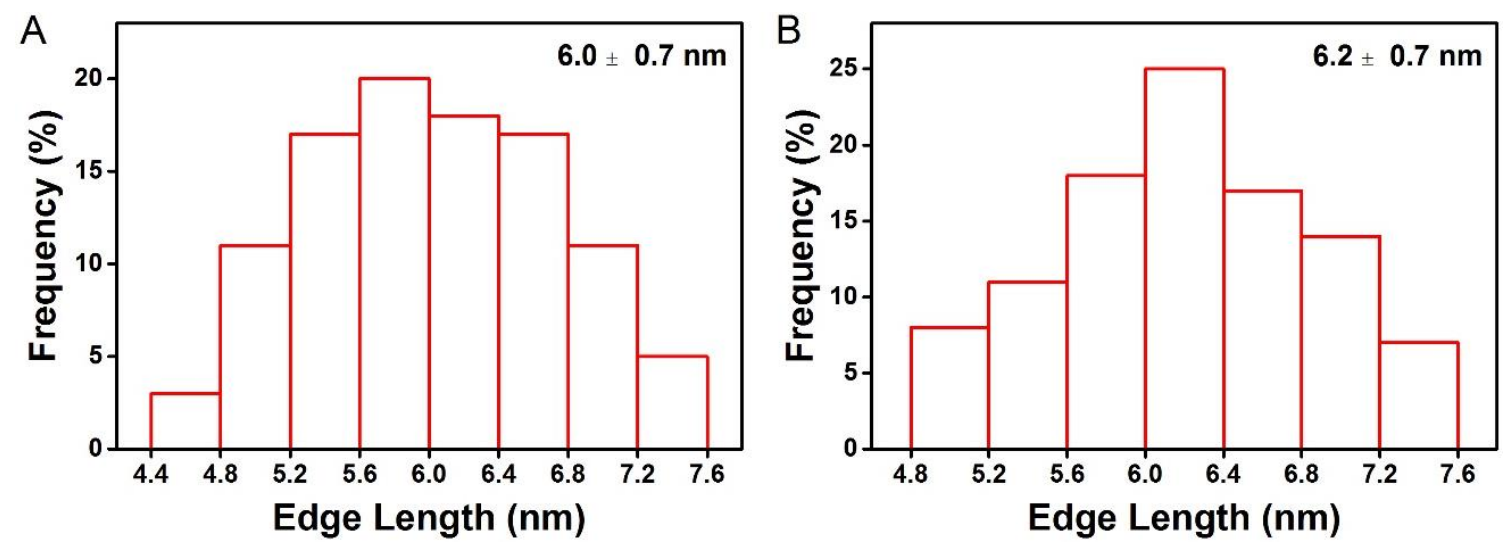

Figure S2. Size distributions of (A) Pd octahedra and (B) PdH octahedra. 

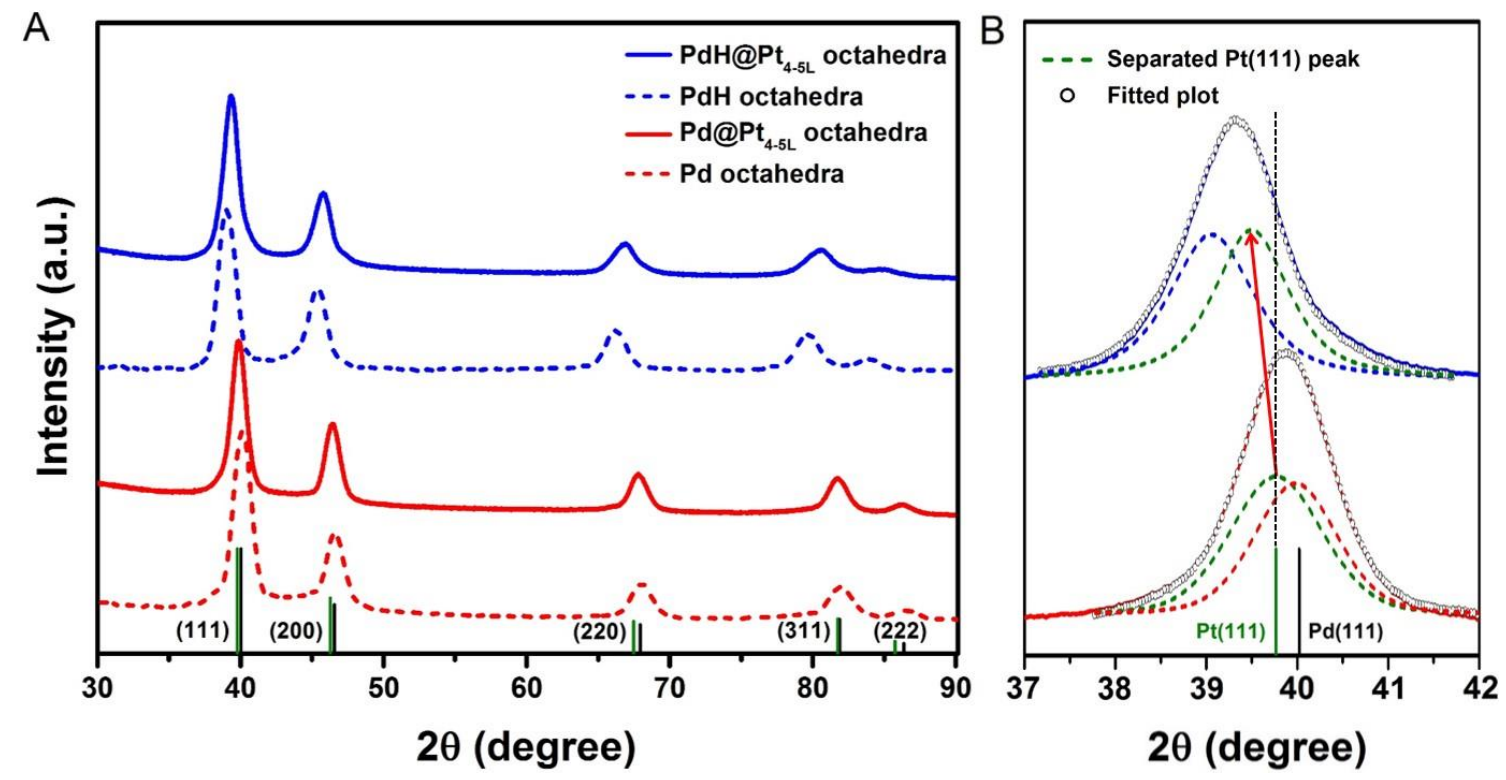

Figure S3. (A) XRD patterns of Pd, PdH, Pd@Pt, and PdH@Pt octahedra. (B) XRD peak separation for the (111) planes of Pd@Pt and PdH@Pt. Black and green vertical lines representing the references of Pd (JCPDS \#00-046-1043) and Pt (JCPDS \#00-004-0802). 

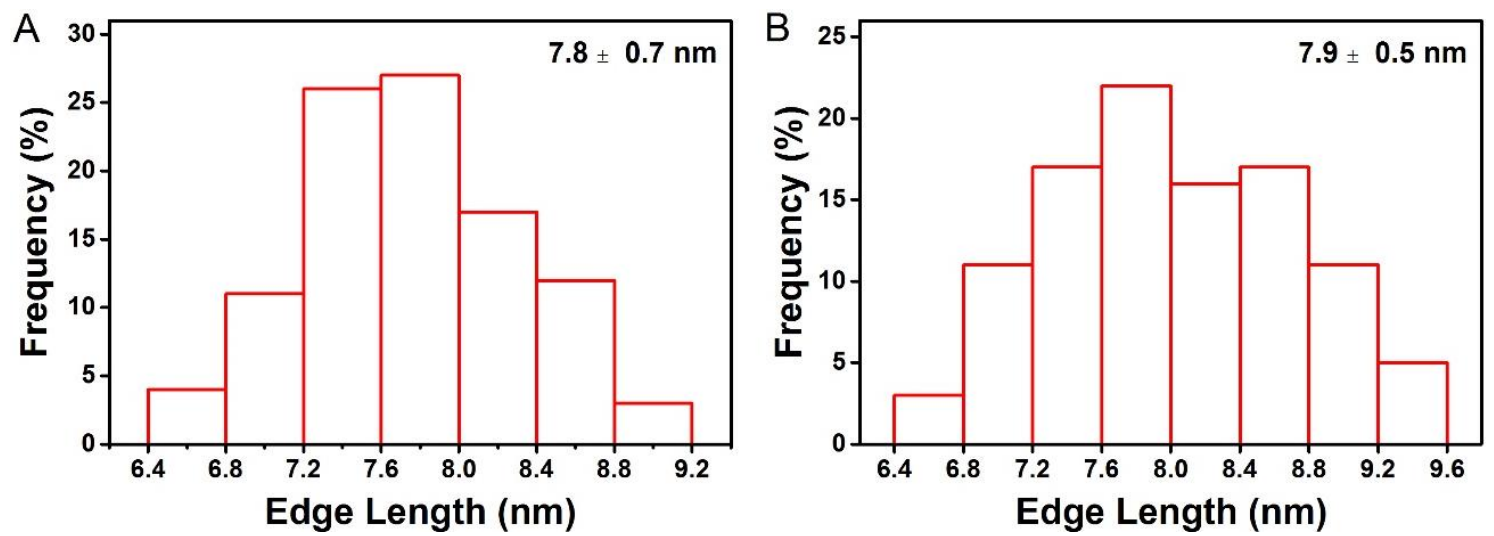

Figure S4. Size distributions of (A) Pd@Pt4-5L and (B) PdH@Pt $\mathrm{Pt}_{4-5 \mathrm{~L}}$ core-shell octahedra. 

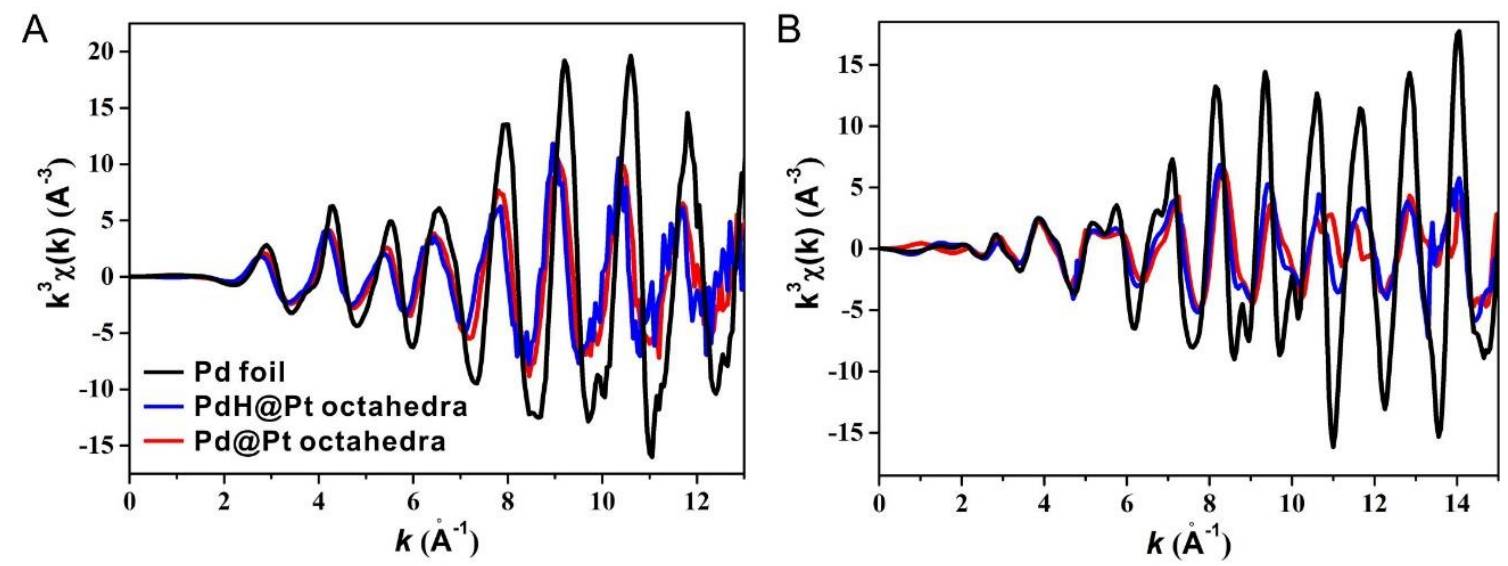

Figure S5. EXAFS k space spectra $\left(\mathrm{k}^{3}\right.$-weighted) of (A) Pd K-edge and (B) Pt $\mathrm{L}_{3}$-edge for the $\mathrm{Pd} @ \mathrm{Pt}_{4-5 \mathrm{~L}}$ and $\mathrm{PdH} @ \mathrm{Pt}_{4-5 \mathrm{~L}}$ octahedra. 

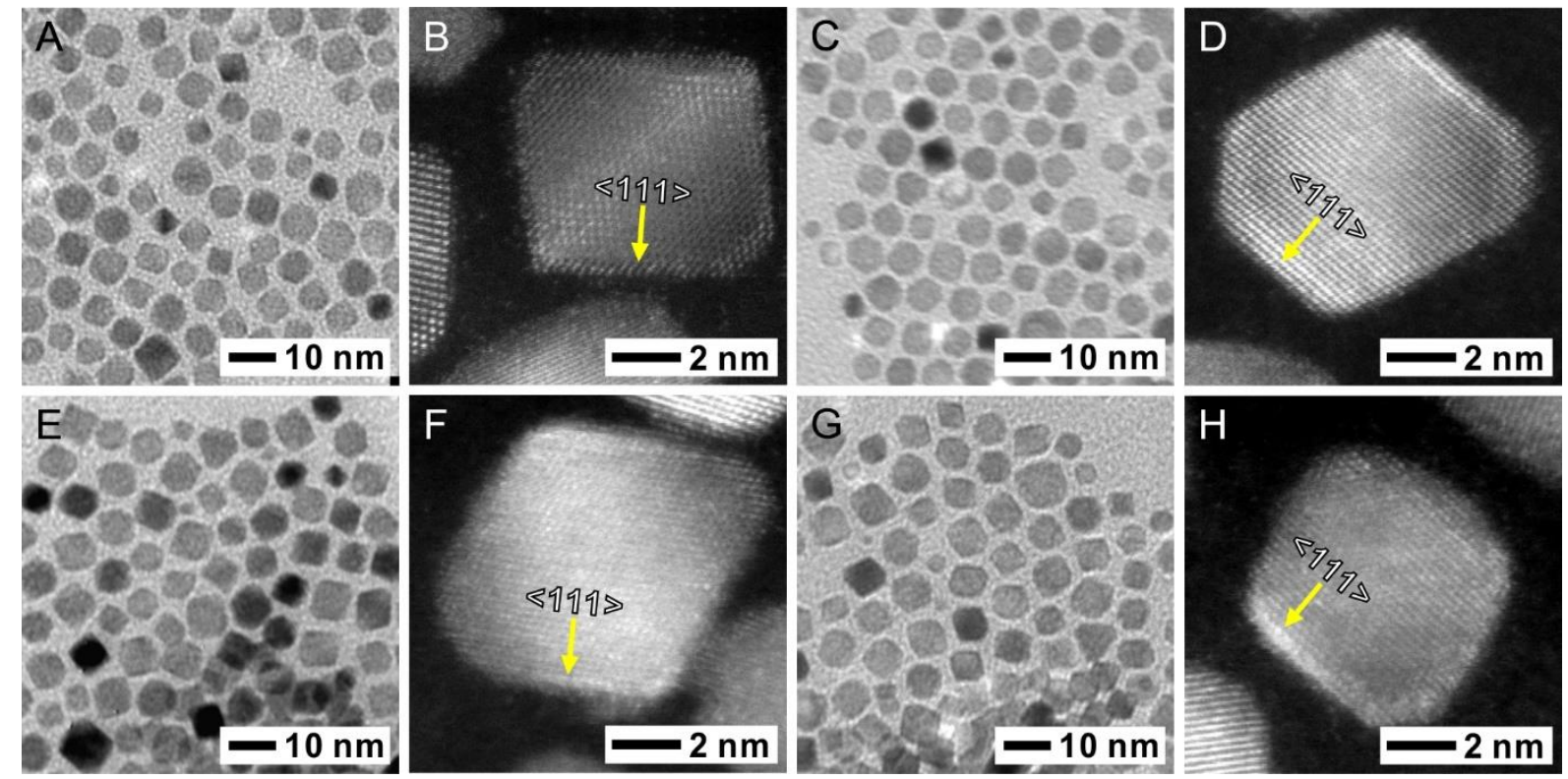

Figure S6. Low-resolution TEM and atomic-resolution HAADF-STEM images of (A, B) $\mathrm{Pd} @ \mathrm{Pt}_{\mathrm{ML}},(\mathrm{C}, \mathrm{D}) \mathrm{Pd} @ \mathrm{Pt}_{2-3 \mathrm{~L}},(\mathrm{E}, \mathrm{F}) \mathrm{PdH} @ \mathrm{Pt} t_{\mathrm{ML}}$, and (G, H) PdH@ $@ \mathrm{Pt}_{2-3 \mathrm{~L}}$ core-shell octahedra. 


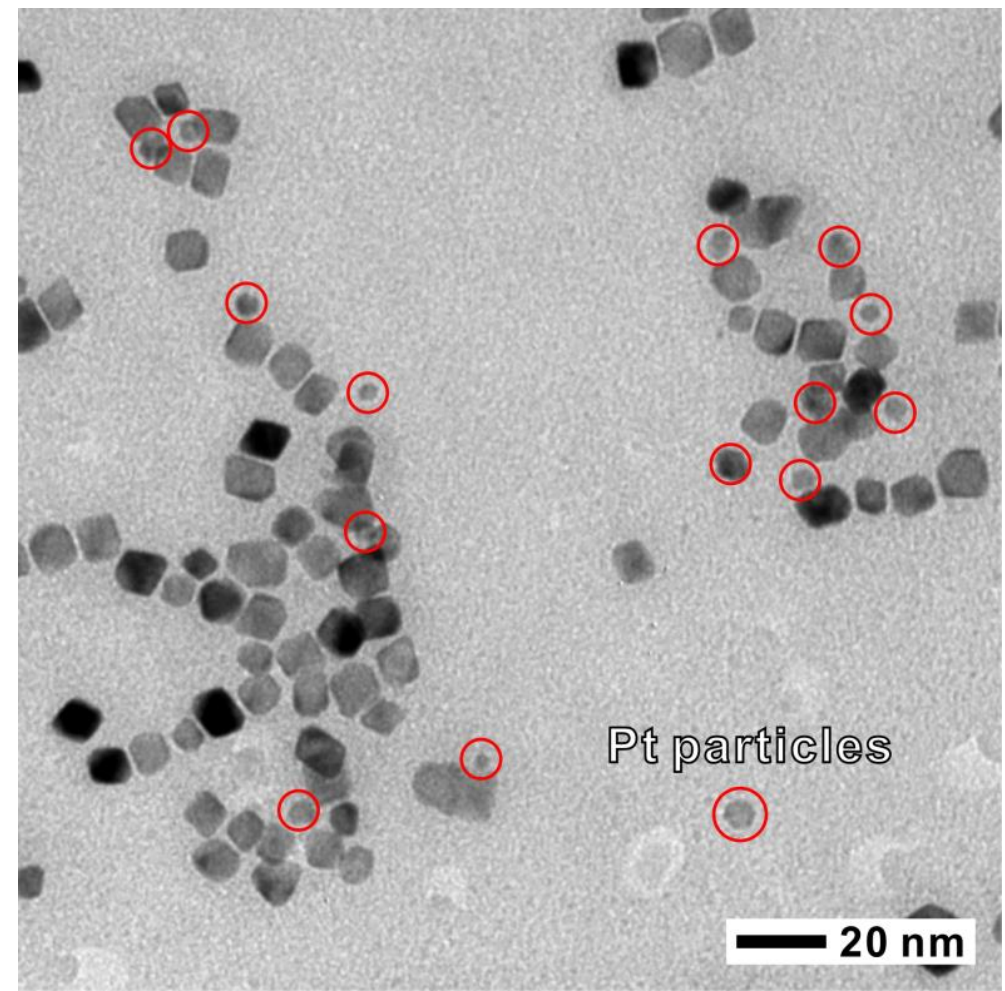

Figure S7. Low-resolution TEM image of Pd@Pt obtained by adding $15 \mathrm{mg}$ of Pt precursor to the standard protocol. 

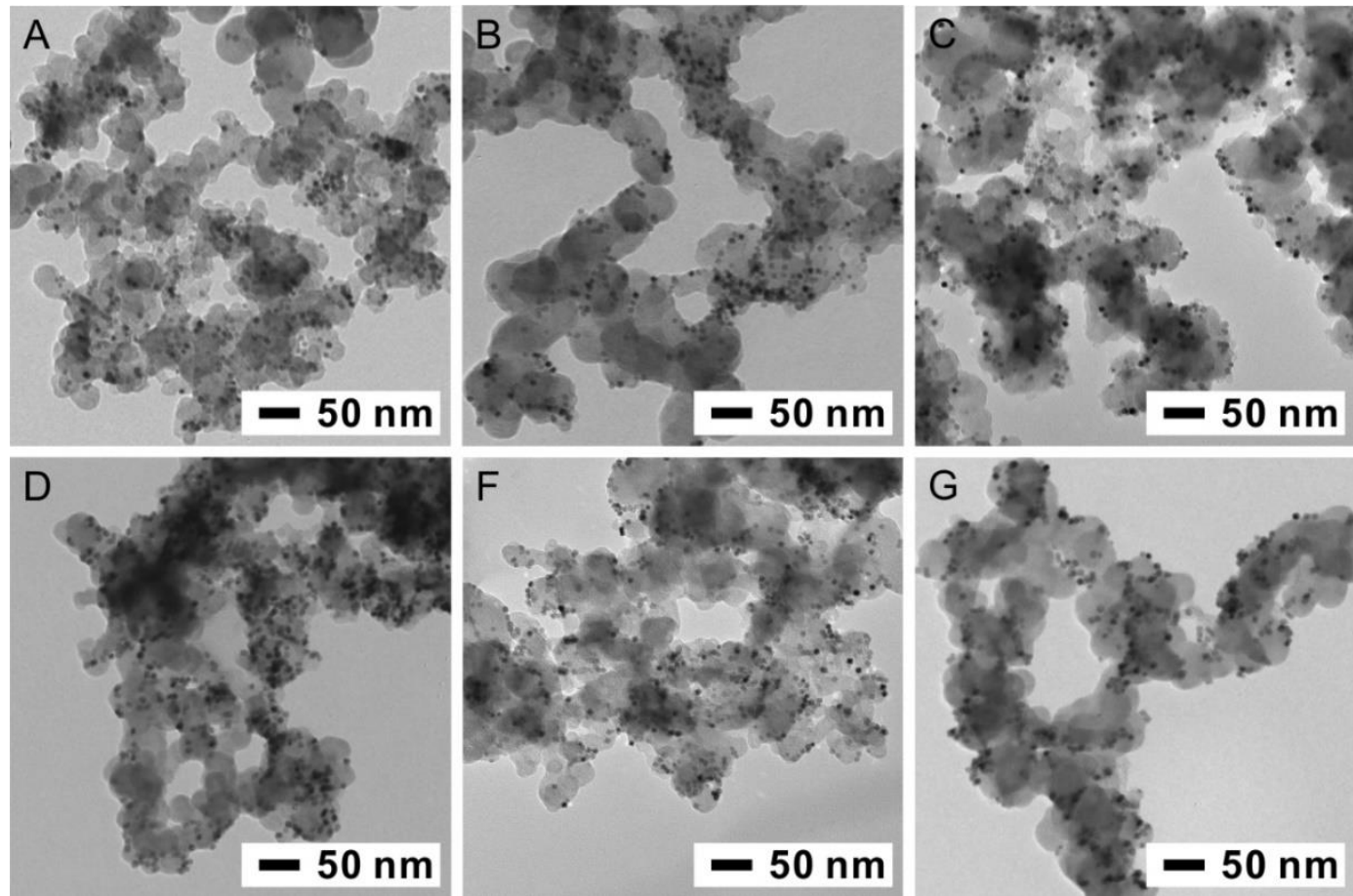

Figure S8. Low-resolution TEM images of (A) Pd@Pt $\mathrm{Pt}_{\mathrm{ML}}$ nanocrystals loaded on carbon support (Pd@Pt $\mathrm{Pt}_{\mathrm{ML}} / \mathrm{C}$ ), (B) $\mathrm{Pd} @ \mathrm{Pt}_{2-3 \mathrm{~L}} / \mathrm{C},(\mathrm{C}) \mathrm{Pd} @ \mathrm{Pt}_{4-5 \mathrm{~L}} / \mathrm{C},(\mathrm{D}) \mathrm{PdH} @ \mathrm{Pt}_{\mathrm{ML}} / \mathrm{C},(\mathrm{E}) \mathrm{PdH} @ \mathrm{Pt}_{2-}$ 3L/C, and (F) PdH@Pt $\mathrm{Pt}_{4-5 \mathrm{~L}} / \mathrm{C}$ catalysts. 

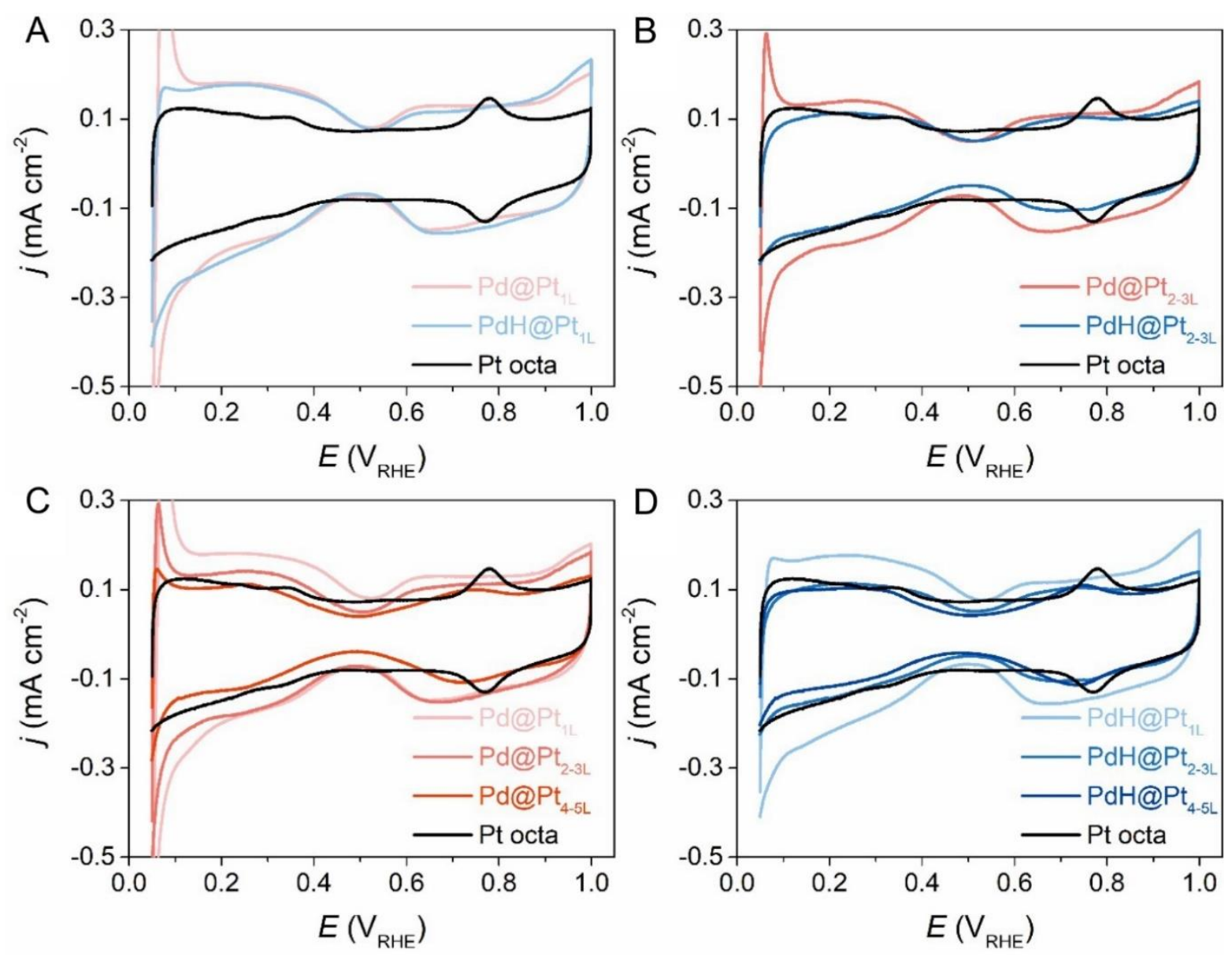

Figure S9. CV responses of Pt@Pt (reddish color) and PdH@Pt (bluish color) in an Arsaturated $0.1 \mathrm{M} \mathrm{KOH}$ electrolyte at a scan rate of $50 \mathrm{mV} \mathrm{s}{ }^{-1} . \mathrm{Pd} @ \mathrm{Pt}$ and PdH@Pt with (A) 1 and (B) 2-3 atomic layers of Pt shell. Effects of the number of the Pt atomic layers on the CV profiles for (C) Pd@Pt and (D) PdH@Pt. A CV of Pt octahedra (black) was also shown for comparison. 

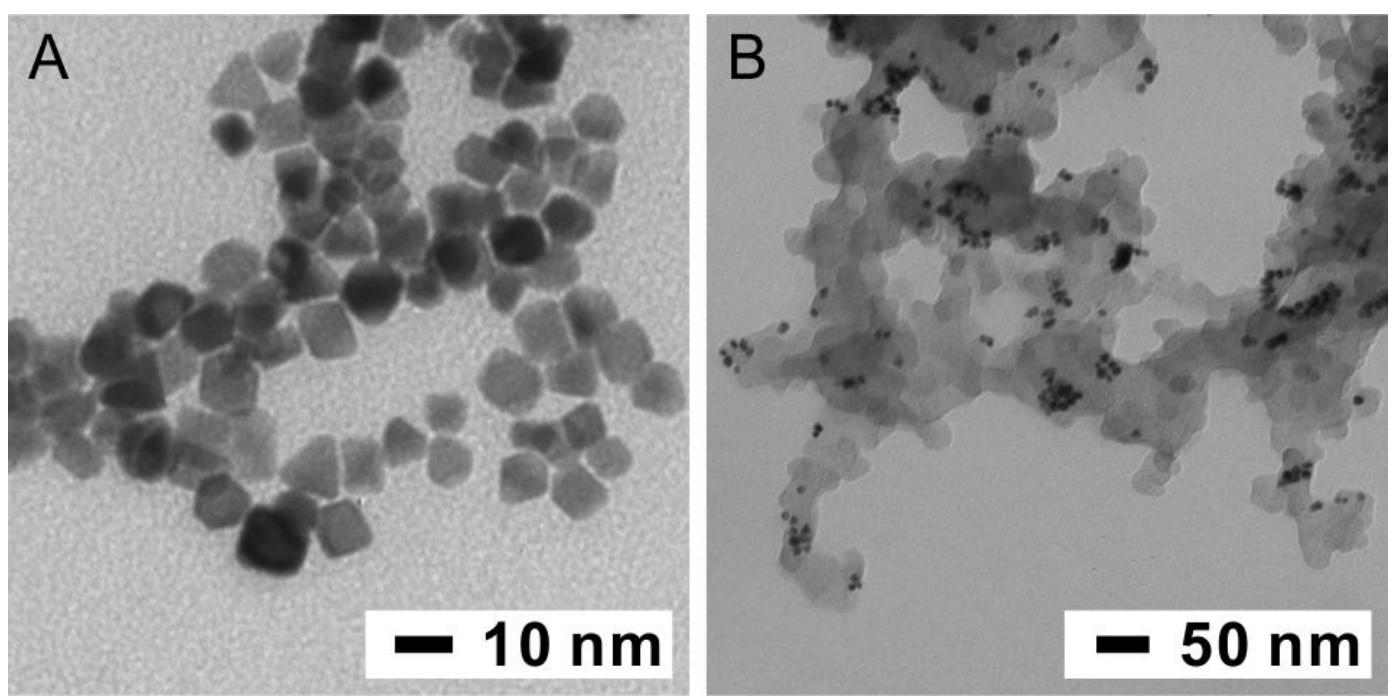

Figure S10. Low-resolution TEM images of (A) as-synthesized Pt octahedra and (B) Pt octahedra/C catalyst. 

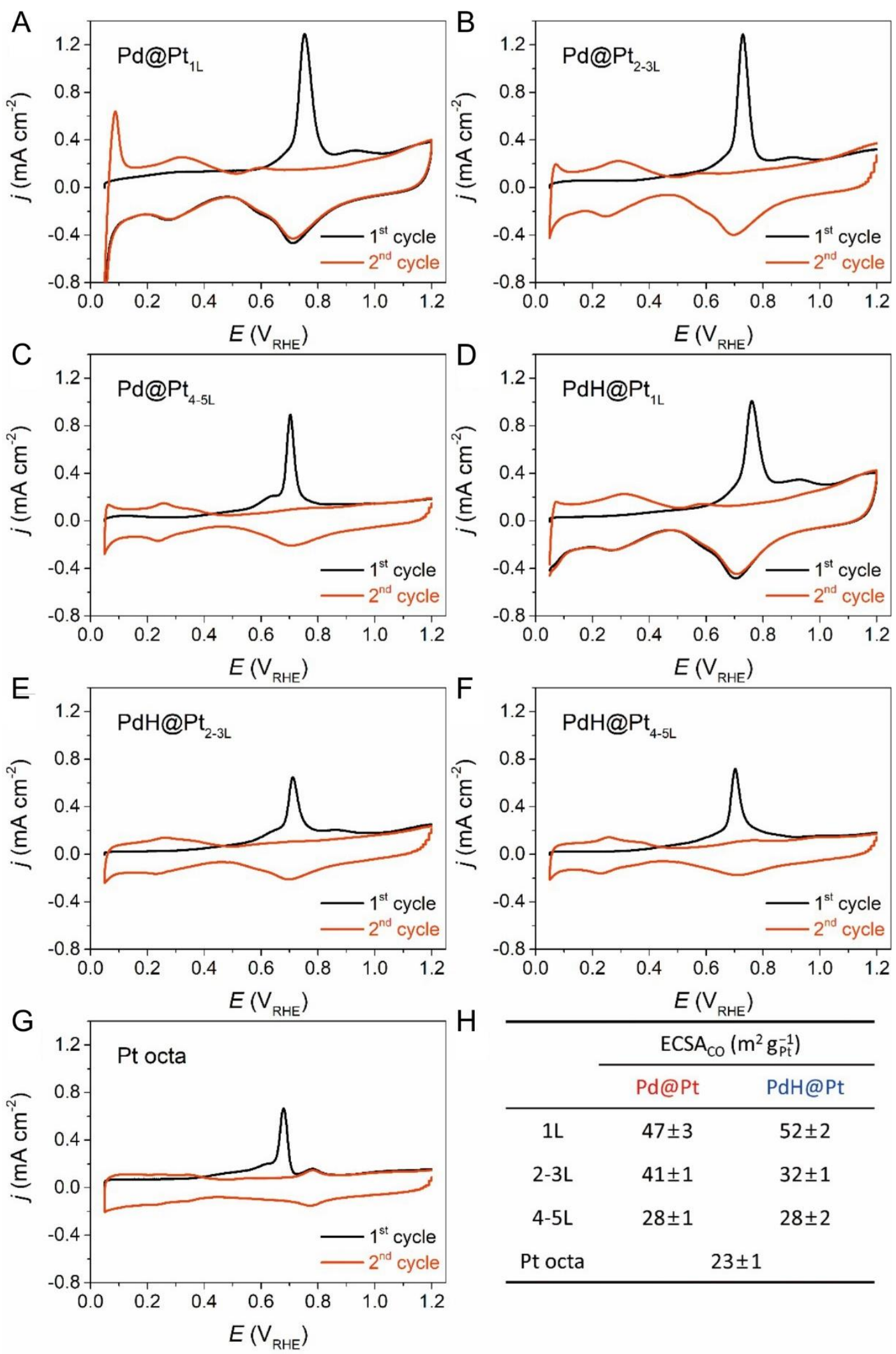

Figure S11. (A-G) CO-stripping profiles of $\mathrm{Pd} @ \mathrm{Pt}, \mathrm{PdH} @ \mathrm{Pt}$, and Pt octahedra at a scan rate of $50 \mathrm{mV} \mathrm{s}^{-1}$ and $(\mathrm{H})$ the measured ECSACO of the catalysts. 

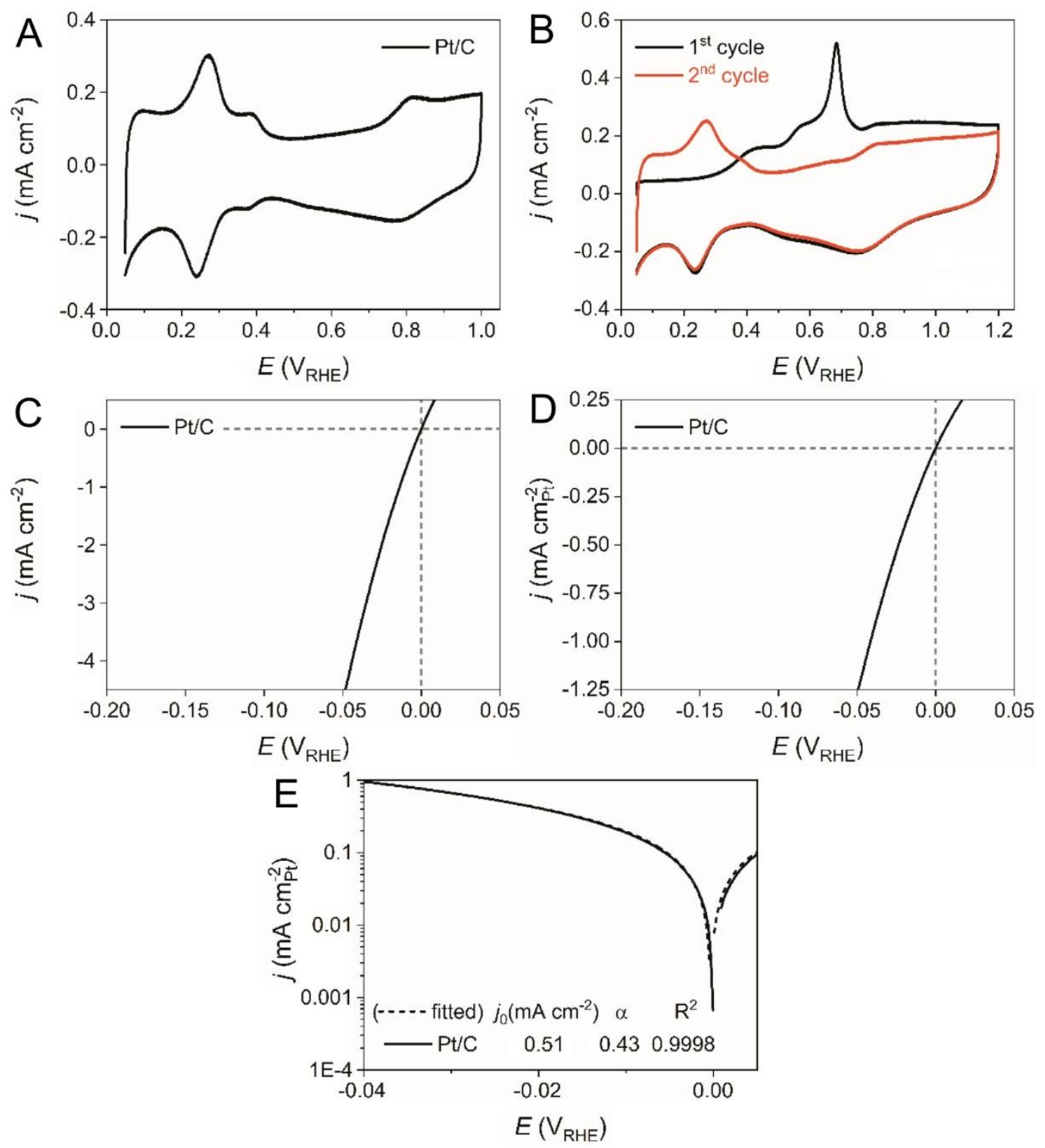

Figure S12. (A) CV response and (B) CO-stripping profile of commercial $\mathrm{Pt} / \mathrm{C}$ catalyst measured at a scan rate of $50 \mathrm{mV} \mathrm{s}^{-1}$ in a $0.1 \mathrm{M} \mathrm{KOH}$ electrolyte. (C) Geometric area- and (D) ECSA-normalized HER polarization curves of the $\mathrm{Pt} / \mathrm{C}$ catalyst measured at a scan rate of 5 $\mathrm{mV} \mathrm{s}^{-1}$ in a $\mathrm{H}_{2}$-saturated $0.1 \mathrm{M} \mathrm{KOH}$ electrolyte. (E) Tafel plot (solid line) of the $\mathrm{Pt} / \mathrm{C}$ catalyst including its Butler-Volmer fitting results (dashed line). The fitting values of $j_{0}, \alpha$, and $\mathrm{R}^{2}$ were noted in the figure. 


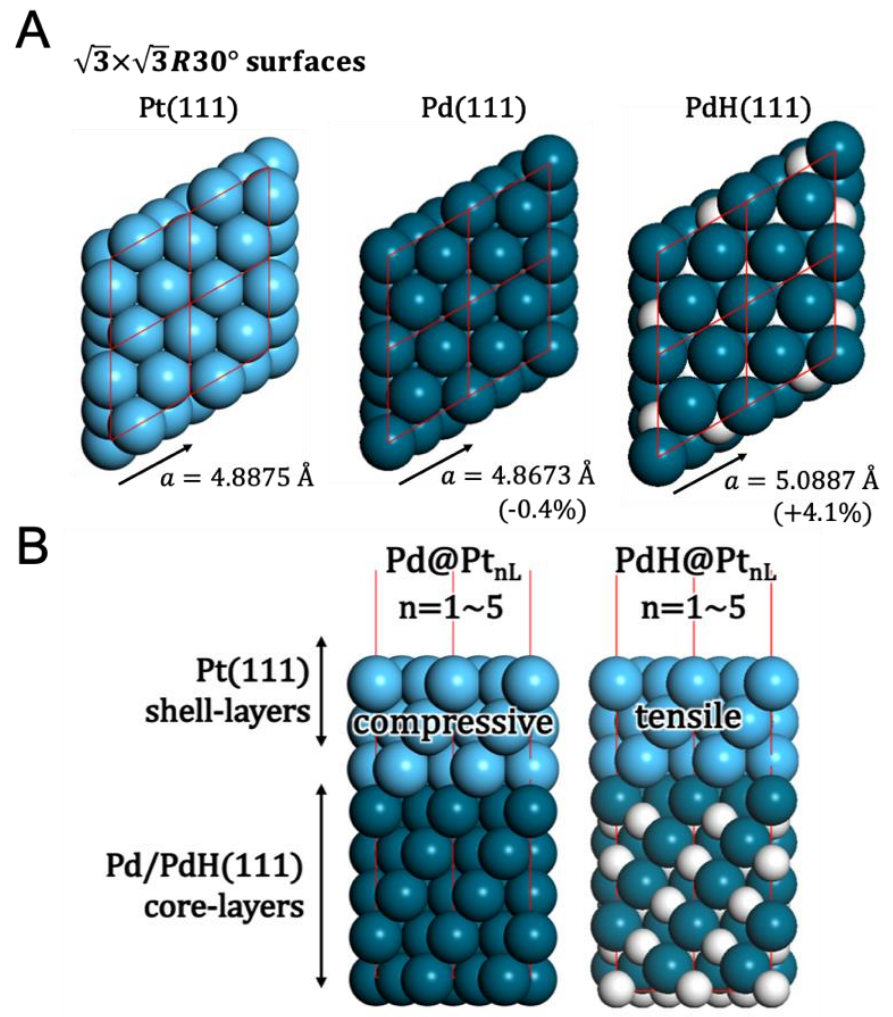

Figure S13. (A) The close-packed (111) $(\sqrt{3} \times \sqrt{3}) R 30^{\circ}$ bare surfaces for the $\mathrm{Pt}, \mathrm{Pd}$, and $\mathrm{PdH}$. Lattice parameter of $\mathrm{Pd}$ is $0.4 \%$ smaller, and that of $\mathrm{PdH}$ is $4.1 \%$ larger than that of the Pt. (B) The core-shell model structures consist of 5 atomic layers of Pd or PdH core with 1 5 layers of Pt shell. For PdH@ $\mathrm{Pt}_{\mathrm{nL}}$ model, the Pt shell layer is added to the Pd dominant surface of $\mathrm{PdH}(111)$ which shows stronger affinity to the Pt shell (-0.14 -0.77 eV/unit-surface). 


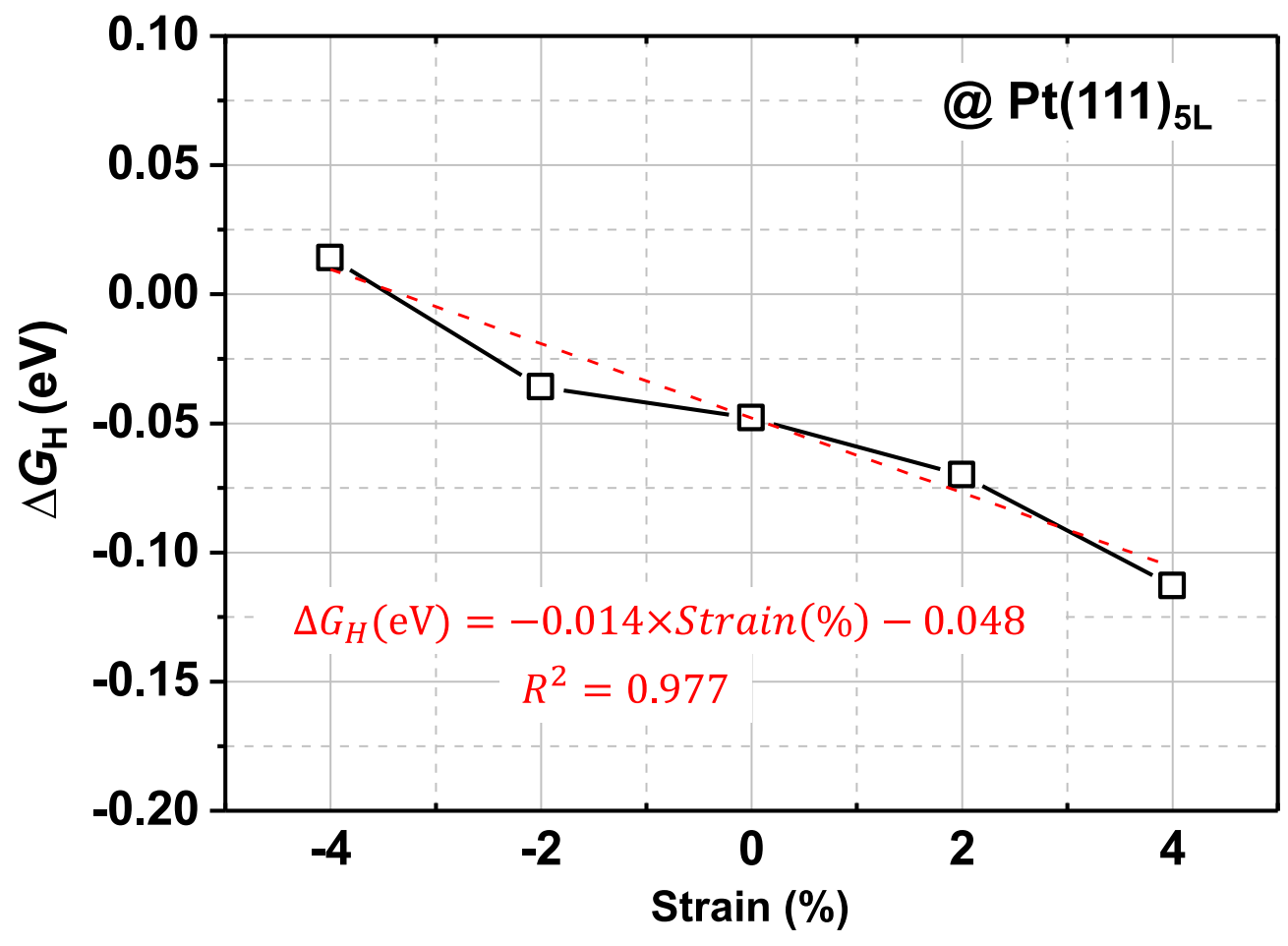

Figure S14. The linear relation between $H$ adsorption free energy $\left(\Delta G_{\mathrm{H}}\right)$ and lattice strain on the ideal Pt(111)5L slab model. 

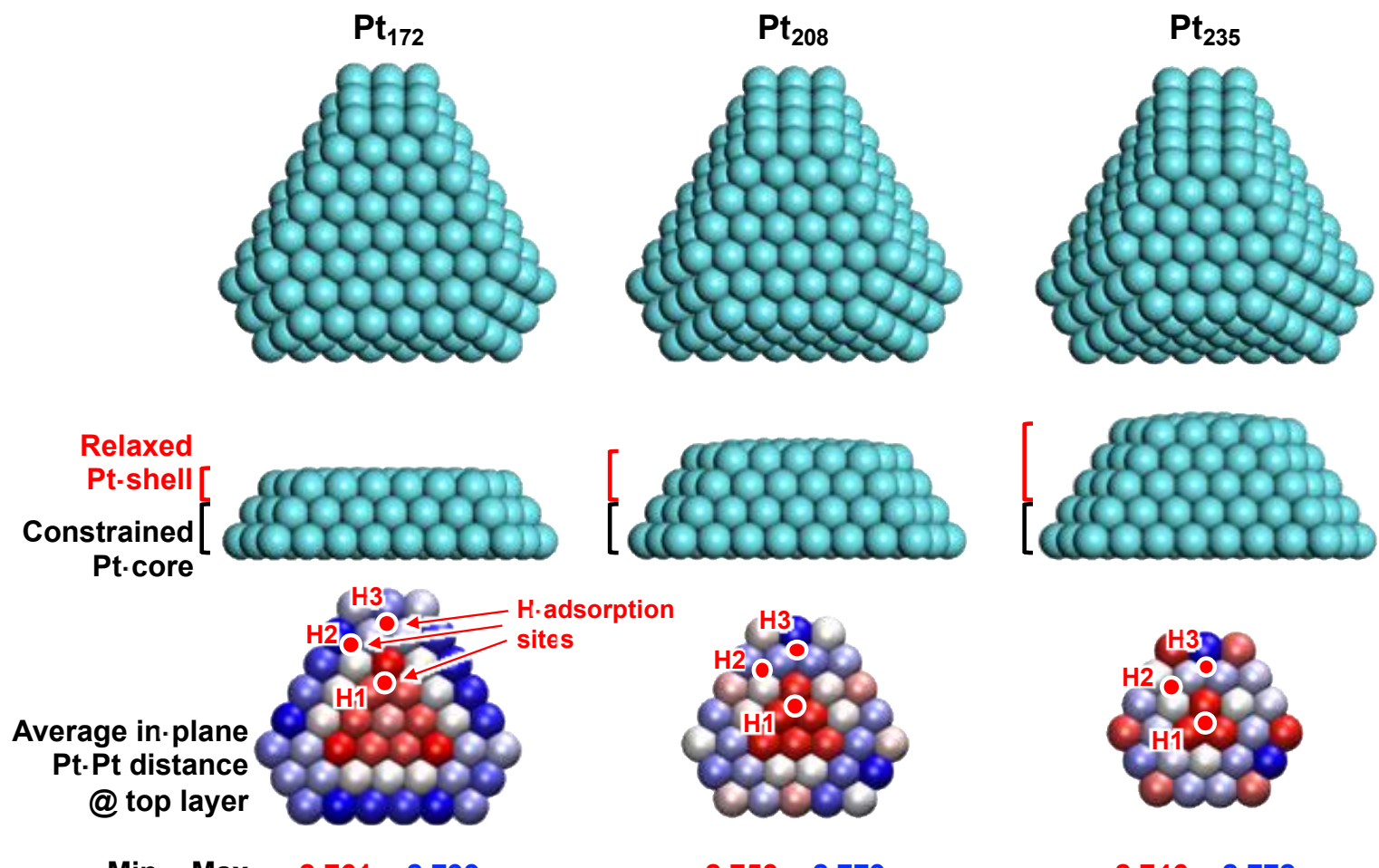

$\operatorname{Min} \sim \operatorname{Max} \quad 2.761 \sim 2.799$

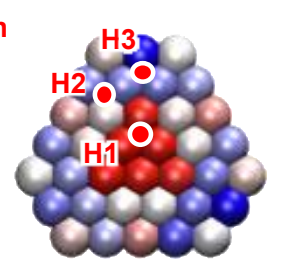

$2.753 \sim 2.779$

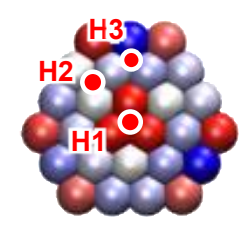

$2.746 \sim 2.772$

Figure S15. The large-scale Pt nanoparticle models based on the truncated octahedron structure. The bottom two surfaces were geometrically constrained to apply strain effect to the Pt shell layers having one to three number of stacked $\mathrm{Pt}(111)$ layers. After geometry optimizations, the average in-plane Pt-Pt distances at the topmost layer were shown by color map. 

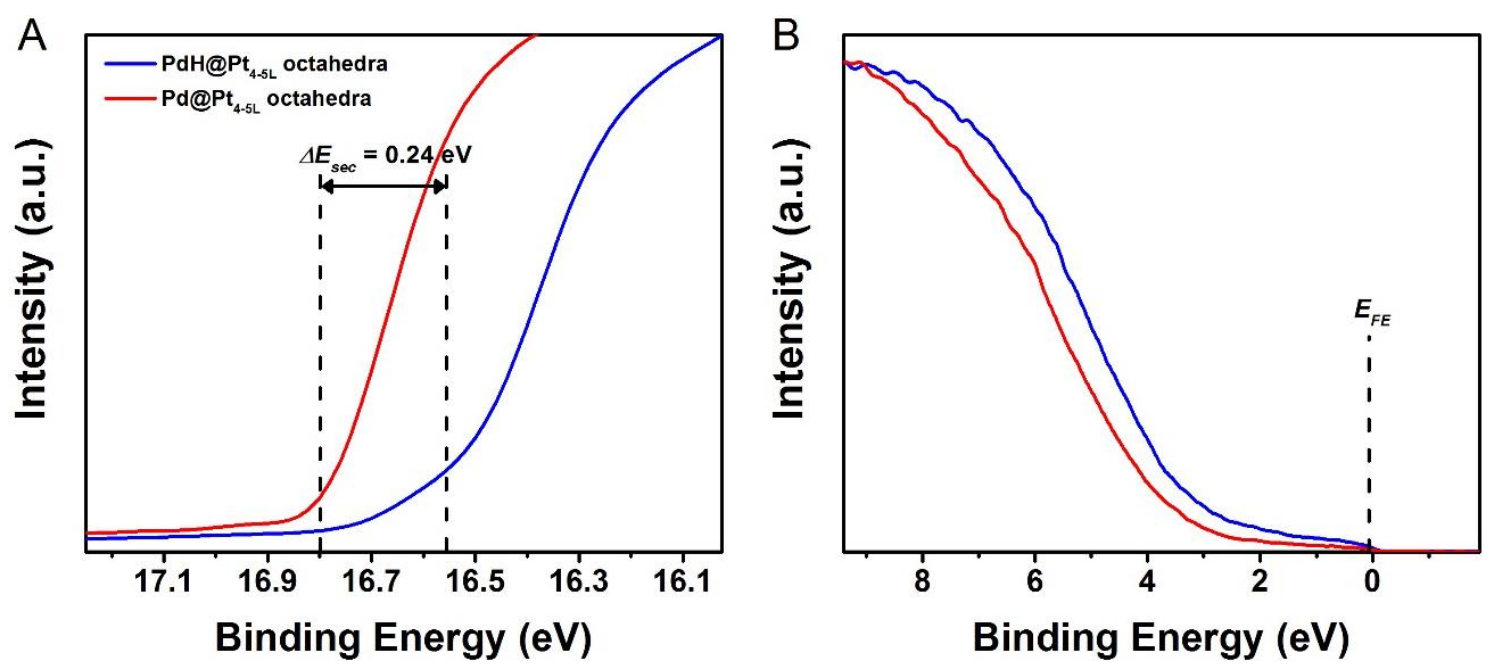

Figure S16. Ultraviolet photoelectron spectroscopy for (A) the region of secondary emission and $(\mathrm{B})$ the region of Fermi edge for $\mathrm{Pd} @ \mathrm{Pt}_{4-5 \mathrm{~L}}$ and $\mathrm{PdH} @ \mathrm{Pt}_{4-5 \mathrm{~L}}$ using a He-I radiation. 
Table S1. Lattice parameters of various Pd-based nanocrystals measured from XRD patterns in Figure S3

\begin{tabular}{cccc}
\hline Sample & $2 \theta$ of $\{111\}$ peak $\left(^{\circ}\right)$ & $\begin{array}{c}\text { Corresponding lattice } \\
\text { parameter }(\mathrm{nm})\end{array}$ & $\begin{array}{c}\text { Approximate } \\
\text { composition }\end{array}$ \\
\hline Pd reference & 40.06 & 0.3890 & $\mathrm{H}: \mathrm{Pd}=0$ \\
Pd octahedra & 40.01 & 0.3898 & $\mathrm{H}: \mathrm{Pd}=0$ \\
PdH octahedra & 39.06 & 0.3995 & $\mathrm{H}: \mathrm{Pd}=0.40$ \\
\hline
\end{tabular}

Table S2. The average number (n) of the Pt atomic layers calculated from the Pd and Pt contents in the $\mathrm{Pd} @ \mathrm{Pt} t_{n L}$ and $\mathrm{PdH} @ \mathrm{Pt}_{\mathrm{nL}}$ octahedra

\begin{tabular}{ccccc}
\hline Sample & $\mathrm{m}_{\mathrm{pt}} / \mathrm{m}_{\mathrm{pd}}$ * & $\begin{array}{c}\text { Thickness } \\
\text { of Pt shell } \\
(\mathrm{nm})\end{array}$ & $\begin{array}{c}\text { Calculated } \\
\text { number of } \\
\text { Pt layers }\end{array}$ & $\begin{array}{c}\text { Number of Pt } \\
\text { atomic layers } \\
\text { for notation }\end{array}$ \\
\hline $\mathrm{Pd} @ \mathrm{Pt}_{\mathrm{ML}}$ & 0.13 & 0.24 & 1.06 & $\mathrm{M}$ \\
$\mathrm{Pd} @ \mathrm{Pt}_{2-3 \mathrm{~L}}$ & 0.52 & 0.63 & 2.81 & $2-3$ \\
$\mathrm{Pd} @ \mathrm{Pt}_{4-5 \mathrm{~L}}$ & 0.83 & 0.94 & 4.18 & $4-5$ \\
\hline $\mathrm{PdH} @ \mathrm{Pt}_{\mathrm{ML}}$ & 0.12 & 0.24 & 1.08 & $\mathrm{M}$ \\
$\mathrm{PdH} @ \mathrm{Pt}_{2-3 \mathrm{~L}}$ & 0.45 & 0.58 & 2.59 & $2-3$ \\
$\mathrm{PdH} @ \mathrm{Pt}_{4-5 \mathrm{~L}}$ & 0.82 & 0.95 & 4.21 & $4-5$ \\
\hline
\end{tabular}

*The mass ratios of $\mathrm{Pt}$ to $\mathrm{Pd}\left(\mathrm{m}_{\mathrm{pt}} / \mathrm{m}_{\mathrm{pd}}\right)$ for the $\mathrm{Pd} @ \mathrm{Pt}_{\mathrm{nL}}$ and $\mathrm{PdH} @ \mathrm{Pt}_{\mathrm{nL}}$ octahedra were obtained from ICP-AES analysis. 
Table S3. The peak positions, the energy differences, and the ratio of peak intensities $\left(\mathrm{I}_{1} / \mathrm{I}_{2}\right)$ for peak 1 and 2 in XANES spectra for samples (Figure 2)

\begin{tabular}{ccccc}
\hline Sample & \multicolumn{2}{c}{ Peak position $(\mathrm{eV})$} & $\begin{array}{c}\text { Peak energy } \\
\text { differences }(\mathrm{eV})\end{array}$ & $\mathrm{I}_{1} / \mathrm{I}_{2}$ ratio \\
& peak 1 & peak 2 & 23.5 & \\
\hline Pd foil & 24350.4 & 24373.9 & 23.0 & 0.8956 \\
Pd@Pt octahedra & 24350.4 & 24373.4 & 20.7 & 0.9303 \\
PdH@Pt octahedra & 24349.5 & 24370.2 & 20.9288 \\
\hline
\end{tabular}

Table S4. The calculated work functions (WFs) and the amount of electron transfer ( $\left.\mathrm{E}_{\mathrm{tf}}\right)$ from $\mathrm{Pd} / \mathrm{PdH}$ core to $\mathrm{Pt}$ shell WFs (unit: $\mathrm{eV}$ ) and $\mathrm{E}_{\mathrm{tf}}$ (in parenthesis, unit: $e$ /unit-surface)

Catalyst for the different \# of Pt shell layers

\begin{tabular}{cccccc} 
& 1 & 2 & 3 & 4 & 5 \\
\hline \multirow{2}{*}{$\mathrm{Pd} @ \mathrm{Pt}_{\mathrm{nL}}$} & 5.15 & 5.14 & 5.08 & 5.13 & 5.08 \\
& $(-0.14)$ & $(-0.06)$ & $(-0.07)$ & $(-0.07)$ & $(-0.07)$ \\
$\mathrm{PdH} @ \mathrm{Pt}_{\mathrm{nL}}$ & 5.38 & 5.37 & 5.42 & 5.35 & 5.38 \\
& $(-0.19)$ & $(-0.11)$ & $(-0.12)$ & $(-0.11)$ & $(-0.12)$ \\
\hline
\end{tabular}




\section{REFERENCES}

(1) Paek, S.-M.; Jung, H.; Park, M.; Lee, J.-K.; Choy, J.-H. An Inorganic Nanohybrid with High Specific Surface Area: $\mathrm{TiO}_{2}$-Pillared $\mathrm{MoS}_{2}$. Chem. Mater. 2005, 17, 3492-3498.

(2) Paek, S.-M.; Jung, H.; Lee, Y.-J.; Park, M.; Hwang, S.-J.; Choy, J.-H. Exfoliation and Reassembling Route to Mesoporous Titania Nanohybrids. Chem. Mater. 2006, 18, 1134-1140.

(3) Kabiraz, M. K.; Kim, J.; Lee, W.-J.; Ruqia, B.; Kim, H. C.; Lee, S.-U.; Kim, J.-R.; Paek, S.-M.; Hong, J. W.; Choi, S.-I. Ligand Effect of Shape-Controlled $\beta$-Palladium Hydride Nanocrystals on Liquid Fuel Oxidation Reactions. Chem. Mater. 2019. 31, 5663-5673.

(4) Choi, S.-I.; Shao, M.; Lu, N.; Ruditskiy, A.; Peng, H.-C.; Park, J.; Guerrero, S.; Wang, J.; Kim, M. J.; Xia, Y. Synthesis and Characterization of Pd@Pt-Ni Core-Shell Octahedra with High Activity toward Oxygen Reduction. ACS Nano 2014, 8, 10363-10371.

(5) Park, J.; Zhang, L.; Choi, S.-I.; Roling, L. T.; Lu, N.; Herron, J. A.; Xie, S.; Wang, J.; Kim, M. J.; Mavrikakis, M.; Xia, Y. Atomic Layer-by-Layer Deposition of Platinum on Palladium Octahedra for Enhanced Catalysts toward the Oxygen Reduction Reaction. ACS Nano 2015, 9 , 2635-2647.

(6) Choi, S.-I. Facile Synthesis of Platinum Octahedra and Cubes through the Manipulation of Reduction Kinetics. Adv. Powder Technol. 2016, 27, 1862-1867.

(7) Mayrhofer, K. J. J.; Wiberg, G. K. H.; Arenz, M. Impact of Glass Corrosion on the Electrocatalysis on Pt Electrodes in Alkaline Electrolyte. J. Electrochem. Soc. 2008, 155, P1P5.

(8) Mayrhofer, K. J. J.; Crampton, A. S.; Wiberg, G. K. H.; Arenz, M. Analysis of the Impact of Individual Glass Constituents on Electrocatalysis on Pt Electrodes in Alkaline Solution. $J$. Electrochem. Soc. 2008, 155, P78-P81.

(9) Björling, A.; Feliu, J. M. Electrochemical Surface Reordering of Pt(111): A Quantification of the Place-Exchange Process. J. Electroanal. Chem. 2011, 662, 17-24.

(10)Rheinländer, P. J.; Herranz, J.; Durst, J.; Gasteiger, H. A. Kinetics of the Hydrogen Oxidation/Evolution Reaction on Polycrystalline Platinum in Alkaline Electrolyte Reaction Order with Respect to Hydrogen Pressure. J. Electrochem. Soc. 2014, 161, F1448-F1457.

(11)Rudi, S.; Cui, C.; Gan, L.; Strasser, P. Comparative Study of the Electrocatalytically Active 
Surface Areas (ECSAs) of Pt Alloy Nanoparticles Evaluated by $\mathrm{H}_{\text {upd }}$ and CO-Stripping Voltammetry. Electrocatalysis 2014, 5, 408-418.

(12)Kresse, G.; Furthmüller, J. Efficient Iterative Schemes for Ab Initio Total-Energy Calculations Using a Plane-Wave Basis Set. Phys. Rev. B 1996, 54, 11169-11186.

(13)Hammer, B.; Hansen, L. B.; Nørskov, J. K. Improved Adsorption Energetics within DensityFunctional Theory Using Revised Perdew-Burke-Ernzerhof Functionals. Phys. Rev. B 1999, 59, $7413-7421$.

(14)Ordejón, P.; Artacho, E.; Soler, J. M. Self-Consistent Order- N Density-Functional Calculations for Very Large Systems. Phys. Rev. B 1996, 53, R10441-R10444.

(15)Hanh, T. T. T.; Takimoto, Y.; Sugino, O. First-Principles Thermodynamic Description of Hydrogen Electroadsorption on the Pt(111) Surface. Surface Science 2014, 625, 104-111. 